\title{
Aluminum Clad Spent Nuclear Fuel Task 1: Oxyhydroxide Layer Behavior and Chemistry Experimental Test Plan
}

\author{
Tedd Lister
}

July 2018

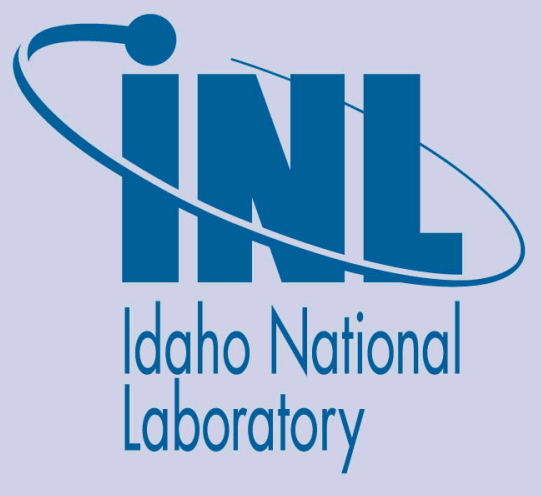

The INL is a U.S. Department of Energy National Laboratory operated by Battelle Energy Alliance 


\section{DISCLAIMER}

This information was prepared as an account of work sponsored by an agency of the U.S. Government. Neither the U.S. Government nor any agency thereof, nor any of their employees, makes any warranty, expressed or implied, or assumes any legal liability or responsibility for the accuracy, completeness, or usefulness, of any information, apparatus, product, or process disclosed, or represents that its use would not infringe privately owned rights. References herein to any specific commercial product, process, or service by trade name, trade mark, manufacturer, or otherwise, does not necessarily constitute or imply its endorsement, recommendation, or favoring by the U.S. Government or any agency thereof. The views and opinions of authors expressed herein do not necessarily state or reflect those of the U.S. Government or any agency thereof. 


\title{
Aluminum Clad Spent Nuclear Fuel Task 1: Oxyhydroxide Layer Behavior and Chemistry Experimental Test Plan
}

\author{
Tedd Lister
}

July 2018

Idaho National Laboratory Idaho Falls, Idaho 83415

http://www.inl.gov

\section{Prepared for the}

U.S. Department of Energy Office of Environmental Management Under DOE Idaho Operations Office Contract DE-AC07-05ID14517 



\title{
Aluminum Clad Spent Nuclear Fuel Task 1: Oxyhydroxide Layer Behavior and Chemistry Experimental Test Plan
}

\author{
INL/EXT-18-45857
}

July 2018

Prepared by:
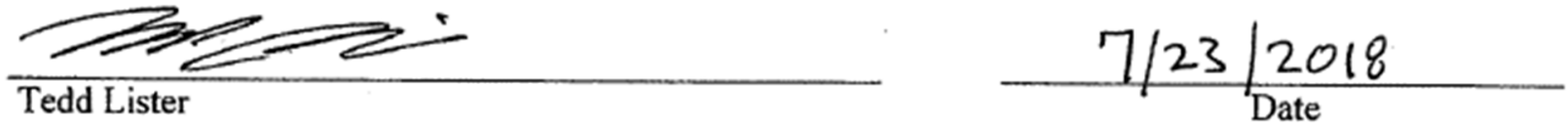

Approved by:

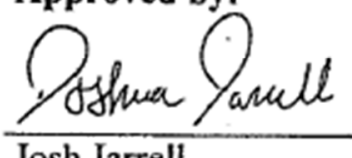

INL Integration Lead
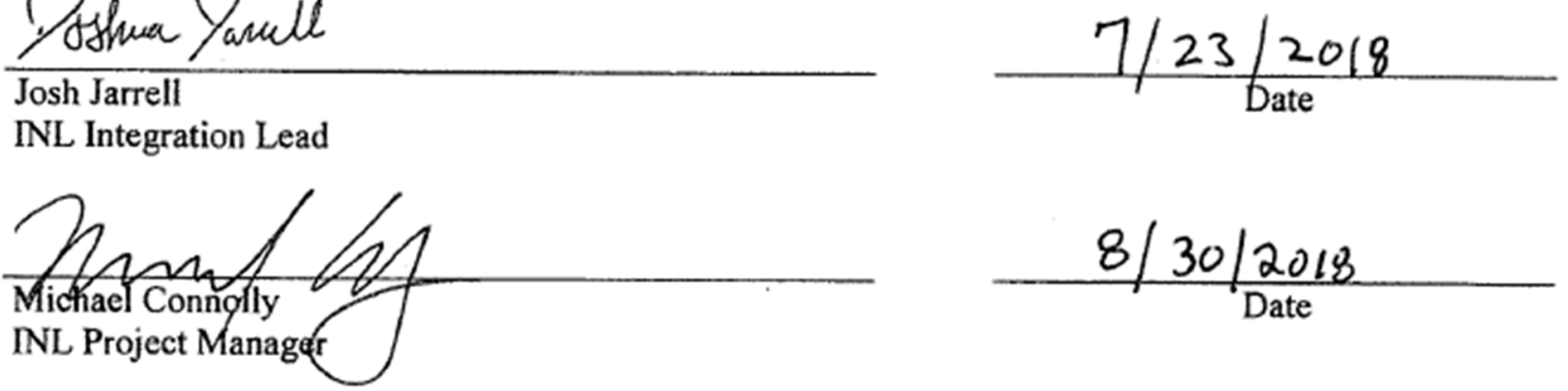



\section{SUMMARY}

This document presents the test plan for Task 1 of the Aluminum Clad Spent Nuclear Fuel Long Term Dry Storage Technical Issues Action Plan, which covers aluminum clad spent nuclear fuel (ASNF) fuel that is currently or may in the future be held in dry storage for an extended period. The objectives of the Task 1 test plan are to:

1. Understand how ASNF performs over extended dry storage periods.

2. Understand mechanisms that could alter aluminum hydroxide/oxyhydroxide layers during extended storage.

3. Characterize thickness and growth rates of oxyhydroxide layers based on fuel history and provide anticipated $\mathrm{H}_{2}$ gas generation rates based on chemical corrosion.

4. Characterize materials properties for oxides present on ASNF.

5. Interface with canister modeling activity to deliver degradation rates for package performance for both sealed and vented configurations.

6. Understand implications of higher temperature drying $\left(250^{\circ} \mathrm{C}\right)$ on stability in dry storage.

This test plan lays out the technical activities that will be performed to achieve the test objectives described above. Experiments will be performed at Idaho National Laboratory in-town facilities. Specimens for testing will include those supplied by Savannah River National Laboratory. Activities will include both experiments and modeling and will coordinate with other tasks within the project. 


\section{CONTENTS}

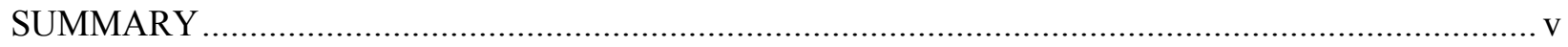

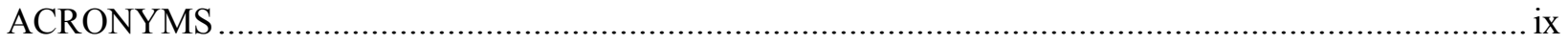

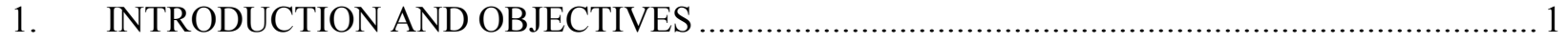

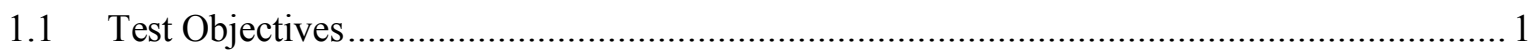

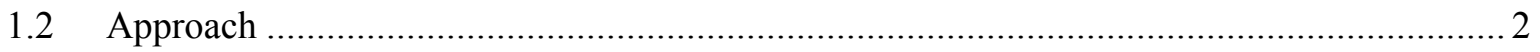

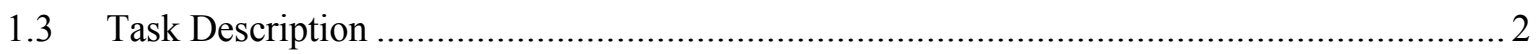

1.3.1 Oxide Film Chemistry and Vapor Corrosion (Subtask 1.1) ............................... 2

1.3.2 Accelerated Corrosion Mechanisms (Subtask 1.2) ........................................... 4

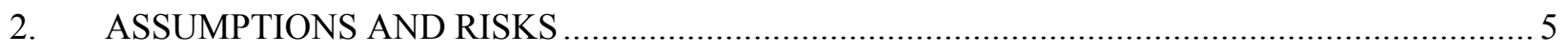

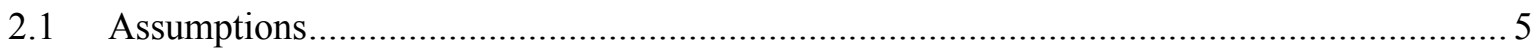

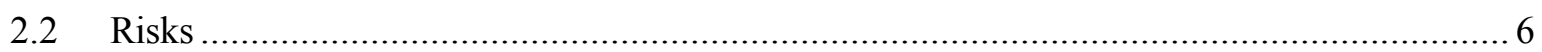

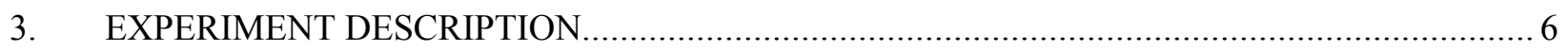

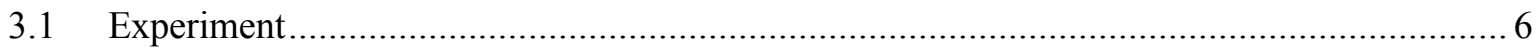

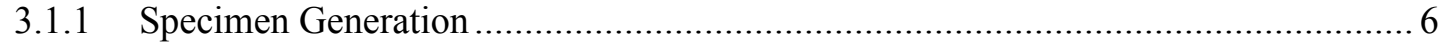

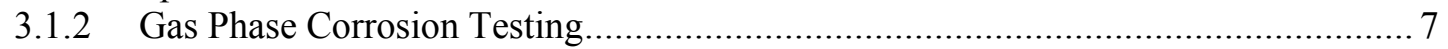

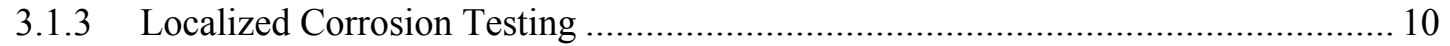

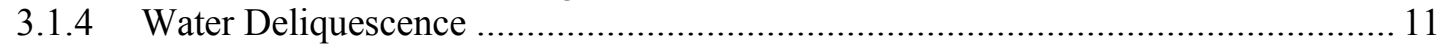

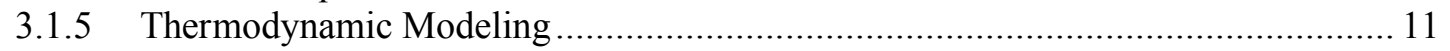

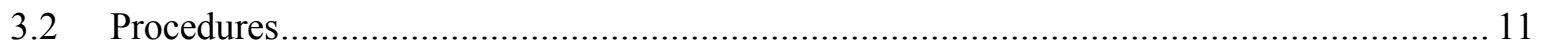

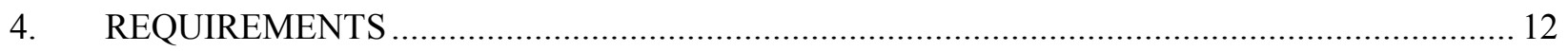

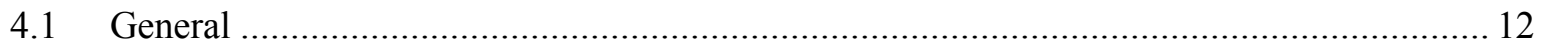

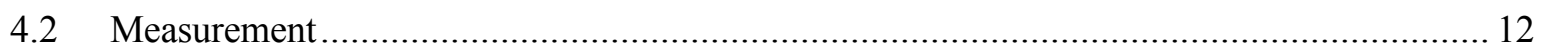

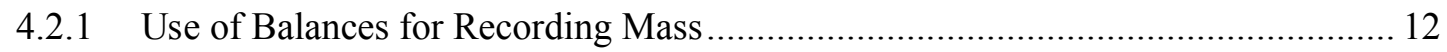

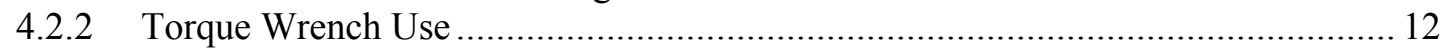

4.2.3 Pipette Water Delivery User Standardization................................................. 12

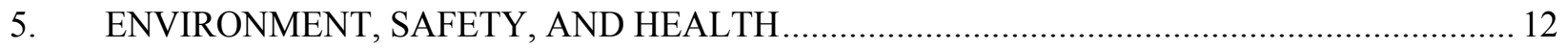

6. QUALITY ASSURANCE AND DATA/RECORD MANAGEMENT …................................ 12

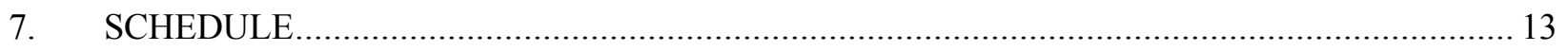

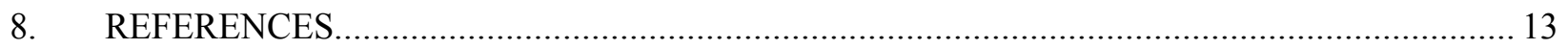




\section{FIGURES}

Figure 1. Vessel for pre-filming of aluminum specimens with an oxide film for Phase 1 activities. ......... 7

Figure 2. Experimental test chamber for assessing reaction of aluminum surfaces with water................ 8

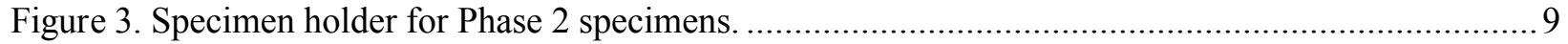

Figure 4. Diagram and image of MCA used for assessing crevice corrosion. ..................................... 10

Figure 5. Experimental diagram of water deliquescence experiments. .............................................. 11

\section{TABLES}

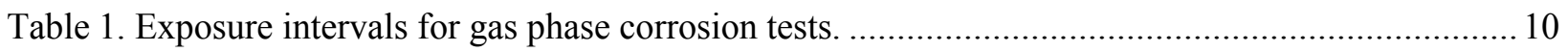

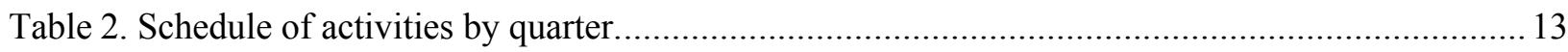




\section{ACRONYMS}

ASME American Society of Mechanical Engineers

ASNF Aluminum clad spent nuclear fuel

ASTM American Society for Testing and Materials

ATR Advanced Test Reactor

DFT Density functional theory

EIL Energy Innovation Laboratory

FY Fiscal year

GC Gas chromatography

ID\# Specimen identification number

IFSF Irradiated Fuel Storage Facility

INL Idaho National Laboratory

LI Laboratory instruction

MCA Multiple crevice assembly

NQA-1 Nuclear Quality Assurance-1

$\%$ RH Percent relative humidity

REC Research and Education Campus

RTR Research test reactor

SEM Scanning electron microscopy

SNF Spent nuclear fuel

SNFWG Spent Nuclear Fuel Working Group

SRNL Savannah River National Laboratory

TGA Thermogravimetric analysis

XRD X-ray diffraction 


\section{Aluminum Clad Spent Nuclear Fuel Task 1: Oxyhydroxide Layer Behavior and Chemistry Experimental Test Plan}

\section{INTRODUCTION AND OBJECTIVES}

The activities performed in Task 1 are based on the recommendations by the Aluminum-Clad Spent Nuclear Fuel Sub Working Group, which were captured in the Aluminum Clad Spent Nuclear Fuel: Technical Considerations and Challenges for Extended (>50 Years) Dry Storage [1]. Following this report, an action plan was formulated to address five areas where additional knowledge was needed to understand the implications of long-term ASNF interim dry storage, as outlined in the Aluminum Clad Spent Nuclear Fuel Long Term Dry Storage Technical Issues Action Plan [2]. The objectives of Task 1 and the approach for the test plan are provided in the sections that follow.

\subsection{Test Objectives}

Task 1 of the Aluminum Clad Spent Nuclear Fuel Long Term Dry Storage Technical Issues Action Plan describes the objectives of this test plan [2]. The first step in assessing how ASNF will perform over extended storage periods is to understand the behavior of oxide/oxyhydroxide films that are created during in-reactor operations and out-of-reactor storage. Film formation is dependent on numerous factors including storage temperature, irradiation history, heat flux, and water quality. Experiments and analysis performed in this test plan will seek to answer three main questions:

- Under what conditions and to what extent do these layers further react to release hydrogen?

- Are there mechanisms which could impact the stability of aluminum oxide/oxyhydroxide layers during extended dry storage?

- Does drying at higher temperature negatively influence cladding stability?

This task will characterize thicknesses and growth rates of oxide layers based on fuel history, characterize and test material properties for the oxides prevalent on ASNF, and assess both corrosion and radiolysis reactions in different oxide layers. Activities to fill this knowledge gap include:

- Growth of representative oxides on aluminum alloy specimens

- Testing of representative specimens in to assess reactivity as function of humidity and temperature

- Employing modeling approach to examine aluminum chemical reactions and phase behavior

- Testing to assess crevice and galvanic corrosion as function of humidity and temperature

- Testing to assess water absorption on aluminum as a function of humidity and temperature.

It is anticipated the results of this task will advance knowledge in:

- Predicting corrosion due to reaction of aluminum cladding with water

- Understanding the behavior of oxide/oxyhydroxide layers under conditions representative of wet and dry storage

- Providing defensible growth rates for oxide layers

- Assessing effects of higher drying conditions on long-term stability. 


\subsection{Approach}

Knowledge gaps in the chemistry of oxide films on ASNF include:

- Thermodynamic data for aluminum oxides and oxyhydroxides at relevant conditions

- Rates of vapor corrosion in sealed and vented canisters at relevant conditions

- Potential for localized corrosion, particularly due to crevice and galvanic contacts

- Water uptake into oxide films as a function of environmental conditions.

To achieve the test objectives outlined above, a combination of experimental and modeling activities will be performed. Experimental activities will assess aluminum water reactions, both general and localized corrosion mechanisms. In addition, the project will examine water deliquescence into aluminum alloys to assess the extent of water filming as a function of relative humidity. Chemical modeling activities will use available thermodynamic data and advanced computational methods to assess aluminum oxyhydroxide chemistry. The sub-tasks will perform the following:

- Examining the thermodynamics and kinetics of oxide films using existing data

- Determining oxide film reactions and assess corrosion as function of varying environmental conditions

- Examining potential mechanisms for accelerated degradation of oxide films as function of varying environmental conditions

- Examining water filming on oxide layers as a function of environmental conditions.

Experimental activities will involve assessing the reaction of ASNF with water. Water is chemically or physically bound to aluminum oxides and is difficult to fully remove from wet storage through drying. Water may also be introduced from local climate for vented canister designs. The task will consider general (uniform) corrosion and localized corrosion as well as assess potential modifiers to local chemical environment. The reaction of aluminum with water is the primary path to hydrogen gas generation, which presents a potential for pressurization [3]. Rapid degradation of the thin aluminum cladding could also occur through localized corrosion. Crevice corrosion is a type of localized corrosion that involves a modified chemical environment due to material pressing again another material such that a tight gap exists. In dry storage, the presence of the gap is particularly important as it can act to wick moisture through capillary action. Galvanic corrosion is also possible due to the anticipated contacts with the canister basket. Contact with stainless steel basket could setup a galvanic cell, where aluminum would preferentially oxidize as the anode of the cell. Surface modifiers to the ASNF are likely due to extended wet storage, where in some cases water was not pure and dirt and even microbial films may be present. This could act to preferentially absorb moisture compared to unmodified aluminum oxides. Thus, experiments will examine water deliquescence on modified aluminum oxides.

\subsection{Task Description}

Task 1 is split into two areas which will perform experiments and analysis to address objects. Subtask 1.1 addresses water reactions and surface chemistry of aluminum oxide layers through experiments and modeling. Subtask 1.2 seeks to assess potential for localized corrosion and assess water adsorption on aluminum surfaces. Testing will be performed using three aluminum alloy types: Al 6061, Al 1100, and Al 5052.

\subsubsection{Oxide Film Chemistry and Vapor Corrosion (Subtask 1.1)}

Examination of aluminum oxide films under relevant storage conditions to more accurately describe the dehydration chemistry as a function of temperature in the range of conditions anticipated for ASNF. Examination will involve both experimental examination coupled with thermodynamic, kinetic and 
density functional theory (DFT) modeling. The goal is to better understand chemistry involved during long dry storage.

\section{Interactions with other tasks:}

Task 3: In - environment / out - $\mathrm{H}_{2}$ gas evolution and oxidation rate

Task 4: Fuel cladding observations (validation)

Task 5: In - Water carryover / out - oxide stability

\subsubsection{Thermodynamic/Kinetic Modeling of Oxide Phases (Subtask 1.1A)}

Thermodynamic modeling of alloy 6061 in different tempers, T6 and O, with layers of boehmite and gibbsite or bayerite as a function of temperature, $\mathrm{pH}$ and the neutronics history of all fuel elements to be transferred to dry storage. Understanding the dependence of growth of gibbsite vs. bayerite as a function of $\mathrm{pH}$ and temperature. Understanding the chemical and phase composition of spent nuclear fuel as a function of its neutronics and thermohydraulics history.

Thermodynamic simulations: It is important to understand the phase and chemical composition of all aluminum alloys (in different tempers) that were used in manufacturing test reactor fuel. Their thermal stability defines the temperature range that can be used for drying SNF before placing it into dry storage. Assessment will consider the highest possible temperature that does not cause phase transformations or recrystallization processes (in the T6 temper). Aluminum forms various oxide phases which may coexist. On the surface of protective boehmite coating the growth of porous, flaky hydroxides may exist. Depending upon the conditions of the neutronics and thermo-hydraulics environment, these might be either gibbsite or bayerite. Understanding the thermodynamics and kinetics of their formation is very important to fully understand the condition of the SNF that will be subjected to drying. It is known that the difference in their enthalpy of formation at normal conditions is slightly above $1 \mathrm{kcal} / \mathrm{mol}$, i.e., very low. Thermodynamic modeling of these hydroxides and studies of their respective thermal stability will help control their growth on the top of the boehmite protective coating.

Atomic/electronic structure calculations: The goal of the atomic simulations is to explore not only the thermal stability of gamma-alumina, boehmite, gibbsite, and bayerite, but also look at the respective interfaces: $\mathrm{Al} / \gamma-\mathrm{Al}_{2} \mathrm{O}_{3} ; \mathrm{Al} / \gamma-\mathrm{AlO}(\mathrm{OH}) ; \gamma-\mathrm{AlO}(\mathrm{OH}) / \gamma-\mathrm{Al}(\mathrm{OH})_{3}$ and $/$ or $/ \gamma-\mathrm{AlO}(\mathrm{OH}) / / \alpha-\mathrm{Al}(\mathrm{OH})_{3}$. The interface structure, impurities and defects to a significant extent define the type of a forming hydroxide and the kinetics of its growth.

Aqueous thermodynamics modeling: This work aims to address the relative solubility of the different oxides, oxy-hydroxides, and hydroxides of aluminum. This includes solubility changes with temperature, and it is very important to have a clear understanding of the conditions existing in these sites applying the most advanced thermodynamics of aqueous systems that is developed today.

Corrosion modeling: This work will provide quantitative estimates of the thermodynamic and kinetic aspects of corrosion of the aluminum alloy cladding in real aqueous environments. Coupled to the planned experimental studies, this work will shed light upon the factors affecting corrosion of aluminum alloy clad in dry storage.

Data Analytics Modeling: In order to understand complex data sets generated in the experimental testing, data analytics be used to draw conclusions from data not possible through conventional analysis. This involves employing modern data analytics techniques (artificial neural networks, Pearson and Taguchi analyses) in order to identify the so-called "descriptors" of the corrosion processes at different stages of the SNF life. This work will support the development experimental program and maximize the information extracted. 


\subsubsection{Vapor Corrosion of Pre-Filmed Aluminum Specimens (Subtask 1.1B)}

This task would experimentally assess corrosion reactions which generate hydrogen gas. This activity will address the concern of hydrogen gas generation in sealed configurations. The assessment will utilize pre-filmed specimens tested at various temperatures and relative humidity. In order to form an oxide growth curve, the experiment will be stopped and specimens weighed and then restarted. The resulting weight gain versus time curves will allow a growth relationship to be made. A sample of gas will be taken prior to each opening of the chamber. The gas will be measured using gas chromatography to determine hydrogen gas composition, a measure of water-aluminum reaction. After an experimental test is completed specimens will be examined using photography, optical microscopy, SEM, and cross-sectional analysis by SEM (film thickness).

\subsubsection{Interface Task (Subtask 1.1C)}

This subtask will perform analysis based on experimental data to provide estimates of hydrogen gas generation and oxidation rate to Task 3 for assessment of environment for sealed and vented canisters. In order to perform under anticipated conditions. This subtask provides an interface with Task 3 to establish a test matrix based on modeled temperature and historic humidity conditions.

\subsubsection{Accelerated Corrosion Mechanisms (Subtask 1.2)}

Examine mechanisms for accelerated degradation of aluminum oxide films and determine what environmental conditions would be required to become active. As pitting corrosion would be observed (if present) in experiments in Subtask 1.1B, it is not specifically included in this subtask. This subtask will specifically examine potential for crevice corrosion and galvanic crevice corrosion (Al alloy coupled with basket). The experiments will employ washers affixed to create the crevice and galvanic conditions.

\section{Interactions with other tasks:}

Task 3: In - environment / out - $\mathrm{H}_{2}$ gas evolution and oxidation rate

Task 4: Fuel cladding observations (validation)

Task 5: In - Water carryover / out - drying temperature

\subsubsection{Localized Corrosion (Subtask 1.2A)}

These tests will examine potential of crevice, galvanic and pitting corrosion and ascertain under what conditions these could occur. Pre-filmed specimens will be used generated using Phase 1 coupons below. The two specific forms of localized corrosion to be examined will be crevice and galvanic corrosion. The tests will employ the same test apparatus used for Subtask 1. Standard crevice corrosion fixtures will be employed to generate multiple crevices sites on each specimen. Crevice corrosion will use assemblies constructed of ceramic material. Galvanic corrosion tests will use metal washers composed of stainless steel used for basket material.

\subsubsection{Capillary Condensation and Deliquescence of Water on Aluminum Surfaces (Subtask 1.2B)}

An assessment will be made on the ability to preferentially adsorb water onto materials entrained on aluminum oxide surfaces. The assessment would be performed by careful application of materials to the surface followed by application water containing environments. The effect of capillary action would be assessed to account for preexisting conditions such as pits or other surface imperfections. Measurement of water entrainment would be assessed using humidity controlled thermogravimetric analysis. 


\section{ASSUMPTIONS AND RISKS}

\subsection{Assumptions}

When performing material evaluations, the desire is to obtain data for assessment in an expedient manner. Inherently, test programs are usually designed to understand behavior involving decades or longer of history and project performance decades into the future. Such is the case with this test plan, where decades of operation have passed and desire to understand performance well into the future. This test plan for Task 1) is part of an overall program that looks at various aspects of ASNF and results must be considered a piece of the overall picture. This test plan covers chemical reactions occurring at ASNF in dry storage. In order to better understand chemical environment and performance, results of Task 2 concerning radiolysis chemistry must also be considered.

An important assumption of the test plan involves the use of surrogate specimens. Surrogate specimens attempt to recreate the chemical and physical properties of materials of interest. As will be described in more detail in Section 3, two types of specimens are being employed as surrogates. This approach was taken due to the challenge of producing enough testing material to provide statistically meaningful results by the most realistic production method. A larger matrix of experiments will be performed with the less realistic specimens. A smaller number of experiments will be performed as validation of the larger test matrix using more realistic (but harder to obtain) specimens. Characterization of both specimens will be performed before use. The assumption for both specimens is that they represent the type of oxides (thickness, microstructure and chemistry) on ASNF.

Another important assumption is that historical "outliers" (ASNF which has experienced unusual treatment during service) will not be specifically considered in this study. Such historical events could be poor chemical control in service or wet storage, physical damage from moving, out of normal operation, exposure to biological or soil debris. This could create a myriad of potential chemical environments that are difficult to recreate in a testing environment. Recreating such conditions is outside of the scope of this test plan, albeit something that could be examined in the future.

The test plan will cover a range of conditions which are thought to be realistic for dry storage, given what we know from observations and Task 3 modeling. Specifically, two documents (EDF-2760 and EDF-7936) provide guidance on thermal conditions from the Irradiated Fuel Storage Facility (IFSF), the only dry storage facility from which to gather information [4-5]. The thermal analysis in EDF-2760 assumes a fully loaded facility with high canister loading where a cladding temperature of $168^{\circ} \mathrm{C}$ was estimated without ventilation. However, a measurement at IFSF was made after a ventilation shutdown outside a package, which using a temperature differential from EDF-2760 led to an estimated temperature of the cladding of $48.2^{\circ} \mathrm{C}$. This leads to the fact is that the temperature of future facilities could vary depending on how the facility is loaded. The conditions used to develop the matrix are provided by Task 3, which will in return receive data for rate of hydrogen generation due to non-radiolytic chemical reactions.

Predicting behavior into the future is a primary goal of materials performance analysis. This test plan aims to provide both numerical rates as a function of conditions as well as provide qualitative information about potential for particular corrosion mechanisms such as crevice and galvanic corrosion. The test plan bases these on values obtained through experiments designed to simulate conditions as best possible using known test methods (ASTM standards) as guidance. However, ASTM guides are developed for common conditions (such as marine corrosion of steel) and must be adapted for use in other environments. This is left up to user discretion on how this is done. 


\subsection{Risks}

The assumptions described above provide limitations in the use of data from the analysis. It is suggested that data collected in this exercise serves the purpose of providing information where little to none exists on ASNF dry storage degradation. To this point, analyses have made conservative assumptions about the reaction with water, including that tightly bound as an oxyhydroxide. The test plan and subsequent use of data in the modeling task will provide a better picture than existed prior.

An important risk to use of data from the test plan is to assume that all chemical reactions are considered in this test plan. Importantly, radiolysis is covered as a separate task, where relatively benign water could become more reactive by radiolytic activation. Thus results of Task 1 and Task 2 activities must be considered as a whole in assessing the chemical stability of ASNF. The program will gather all data into a cohesive package through Task 3 , which mitigate this risk.

There will always be a risk in performing laboratory experiments in order to assess real world conditions. It is simply impossible to precisely simulate the long service period ASNF has experienced. The test plan has taken the approach in attempting to use realistically produced specimens as a starting point. The conditions developed for the test matrix come from best assessments provided by Task 3 .

Projecting future performance using a short timescale described in the test plan is standard practice in materials performance. Given limited time and resources, this test plan uses shorter time scales to predict long-term performance. An important point concerning this is that ASNF will experience what is expected to be reduction in reactive conditions over time. Cooling from reduced nuclear heating over time and drying from water-metal reactions to generate oxides, at least for sealed systems. Corrosion is a chemical reaction, thus rates are generally accelerated by temperature and water is a requirement for continued reaction, where concentration of humidity provides a driving force through equilibria.

\section{EXPERIMENT DESCRIPTION}

\subsection{Experiment}

This section defines the experimental systems used to perform work scope described in Section 1.

\subsubsection{Specimen Generation}

Test specimens will be prefilmed with a thick oxide layer to best mimic those for ASNF. Prefilming will be performed using two methods:

- Phase 1 specimens will form the bulk of test specimens due to the ease of producing in parallel in a single bath.

- Phase 2 specimens, considered to be a more accurate representation of ASNF filming, will be produced by Task 6 at SRNL and will be used to confirm Phase 1 data.

\subsubsection{Generation of Phase 1 Aluminum Specimens}

Initial testing will involve the generation of aluminum specimens prepared by a hot water bath at the INL such as shown in Figure 1. Aluminum specimens will be suspended in the vessel using a glass structure with hanging hooks such that they are fully immersed in deionized water and do not touch each other. Each specimen will be weighed and photographed before and after exposure. After being exposed at $95^{\circ} \mathrm{C}$ to generate a boehmite film, specimens will be removed, weighed and photographed. To simulate conversion to trihydroxides, the specimens will be exposed to room temperature deionized water for an additional exposure time. After the second exposure each specimen will be weighed and photographed. A witness specimen for each alloy type will be interrogated in detail after both exposures. This will involve using SEM as well as cross-sectional SEM to assess the oxide film thickness. 


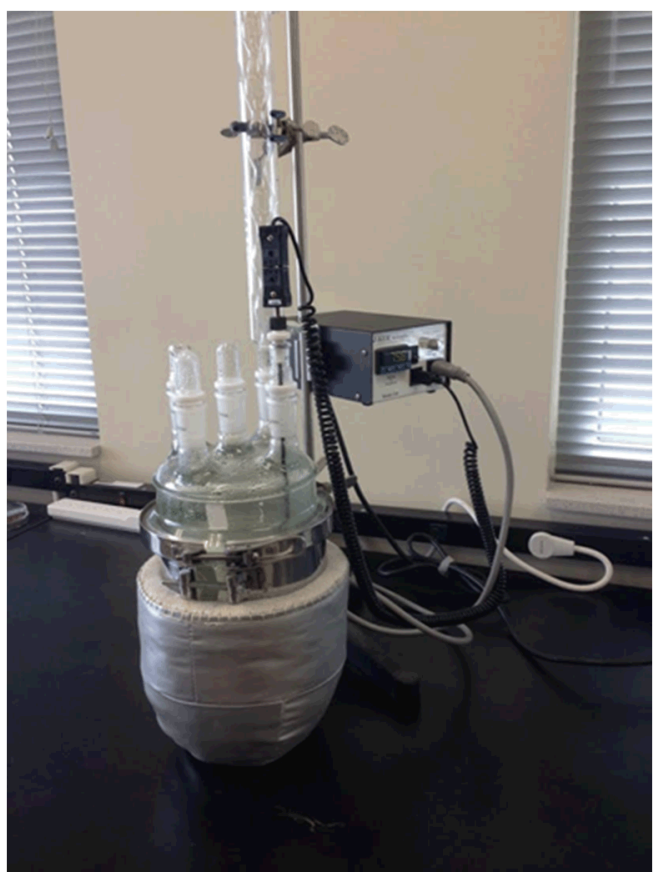

Figure 1. Vessel for pre-filming of aluminum specimens with an oxide film for Phase 1 activities.

A special case surrogate will also be produced to consider high temperature drying under vacuum. Specimens that have already been treated to hot water exposure will subsequently be exposed to $250^{\circ} \mathrm{C}$ in a vacuum oven for a short time to simulate that exposure.

\subsubsection{Generation of Phase 2 Aluminum Specimens}

Specimens used for Phase 2 testing will be obtained from SRNL (Task 6) and a complete chemical characterization will have been performed prior and will not be repeated. These specimens will be treated using a hot-wall apparatus to more realistically apply an oxide layer on one side.

\subsubsection{Gas Phase Corrosion Testing}

In Figure 2 below, a diagram of a closed-volume chamber is shown. The enclosure will be constructed of corrosion resistant stainless steels with a fixed end sealed using a threaded flange or welded flange. The end caps are removable, where specimens will be introduced at one end. The humidity will be controlled by addition of a controlled amount of water determined through gas law calculation. The volume will be filled with dry air as loading is performed except for when $100 \% \mathrm{RH}$ is tested. A thermocouple will be employed to control temperature near the sample. The sample port would be used to assess gas composition as each interval is ended.

Before operation, the test chamber must be leak tested. This should be performed by pressurizing with helium gas and using an appropriate leak detector. Alternatively, pressure may be introduced (50-100 PSI) and the leak down rate observed with a pressure gauge over many hours. No decrease in pressure should be observed. A poorly sealed chamber will result is drying of the chamber as the test progresses. 


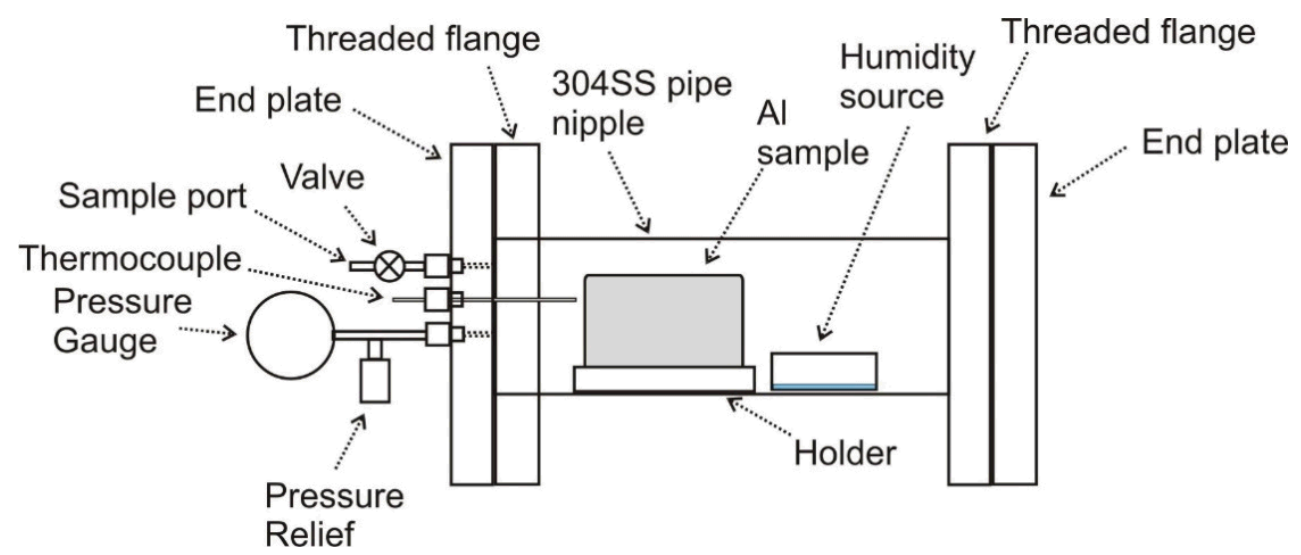

Figure 2. Experimental test chamber for assessing reaction of aluminum surfaces with water.

Experiments will be operated in parallel using multiple test chambers to facilitate a larger data set covering relevant conditions. Heat tape wrapped on the chamber exterior will be used to heat vessel via an appropriate controller. A cover blanket or wrap will be located around the tube to promote uniform temperature. The specimens will be isolated from the outer stainless steel body using a plastic holder. Three specimens per test will be employed.

In order to construct an oxidation/corrosion curve, the specimen needs to be weighed several times during a test. This requires using several test intervals, where between each interval the chamber is opened to allow specimens to be weighed. The following steps are involved:

1. Sample gas by opening a valve to release pressure into a metal lined Tedlar bag.

2. Turn off heater and cool the chamber.

3. Open chamber and remove specimens.

4. Weigh specimens on a balance.

5. Return specimens to chamber.

6. Ensure chamber is dry.

7. Add water to chamber and close.

8. Resume heating. 
After the test is complete (the test intervals completed) and final weighing complete, specimens will be visually inspected and photographs taken. Examination of at least one specimen per experiment will ensue. This will include optical microscopy, SEM, and cross-sectional SEM analysis. Experiments will collect the following data:

1. Hydrogen gas composition through air sampling and gas chromatography (GC).

2. Weight change through weighing on 5 place balance at end of each interval.

3. Photographs of specimens after exposure.

4. Scanning electron microscopy (SEM) of specimen surface.

5. X-ray diffraction (XRD) to identify oxide phases.

6. Cross-sectional analysis through metallographic preparation and SEM.

These data will act of complimentary and confirmatory in the assessment of aluminum corrosion rate. The measurement of hydrogen gas and weight gain will provide complimentary measures of wateraluminum reaction rate. Photographs and surface will identify the presence of localized corrosion. SEM and XRD will assess microstructure and identify oxide phases. Finally, cross-sectional analysis will provide measurement of oxide film thickness and can be compared to a witness specimen of that alloy type and pretreatment batch.

Two types of specimens will be used, designated at Phase 1 and Phase 2, produced as described in Section 3.1. Phase 1 specimens are treated on all exposed surfaces and thus can be inserted into the test chamber with only a simple holder to keep in position and prevent contact to vessel sides. Phase 2 specimens are treated only on one surface, thus a special holder will be employed as shown in Figure 3. The holder prevents contact of the atmosphere to the unexposed surfaces.
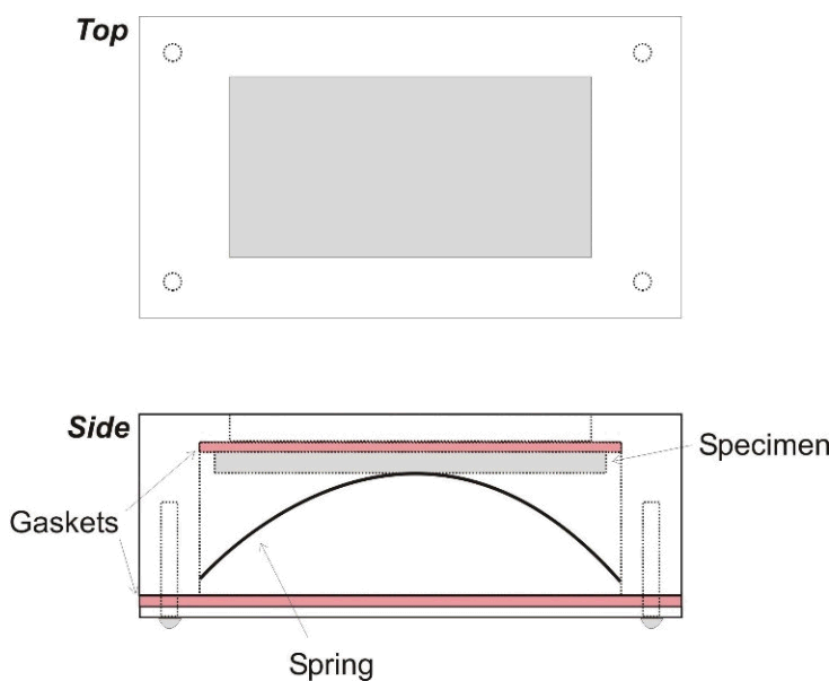

Figure 3. Specimen holder for Phase 2 specimens.

A matrix of conditions will be tested using conditions which are realistic for dry storage:

- Temperature range of 20 to $190^{\circ} \mathrm{C}$.

- Relative humidity range of 25 to $100 \%$.

The interval times for each experiment are provided in Table 1 below. As the experiment proceeds the length increases. This design allows the anticipated parabolic growth curves to be measured using a minimum of points. The times are suggested and do not have to be rigidly followed. 
Table 1. Exposure intervals for gas phase corrosion tests.

\begin{tabular}{|l|l|l|}
\hline Interval & Days & Hours \\
\hline 1 & 2 & 48 \\
\hline 2 & 7 & 168 \\
\hline 3 & 14 & 336 \\
\hline 4 & 21 & 504 \\
\hline
\end{tabular}

\subsubsection{Localized Corrosion Testing}

The test chamber shown in Figure 2 will be supplemented with test specimens that consider effects of crevices and galvanic couples. The fixtures will be based on established methods for assessing crevice and galvanic corrosion. Crevice corrosion will use ceramic washers such as shown in Figure 4. A multiple crevice assembly (MCA) is commonly used, which creates several similar crevice environments. Galvanic corrosion test fixtures will be of a similar configuration, with metal washers employed. The washers are tightened using a torque wrench to specified torque. Bolts are to be electrically insulated from specimens to prevent galvanic contacts.

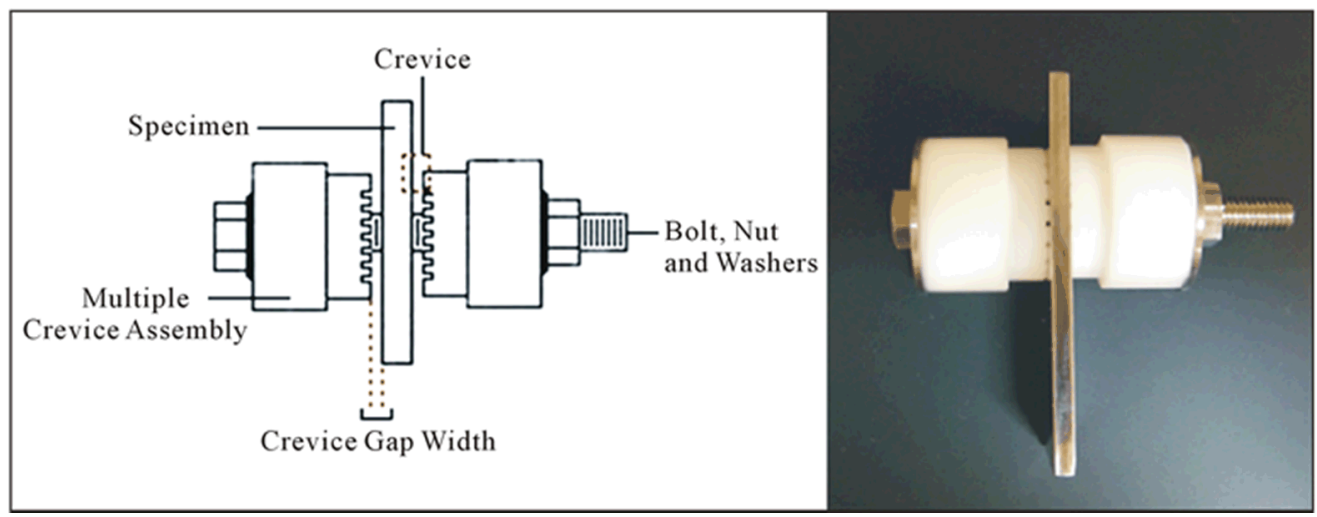

Figure 4. Diagram and image of MCA used for assessing crevice corrosion.

Unlike the gas phase corrosion tests, a growth curve is not the goal of localized corrosion testing. Specimen weight will be recorded, but testing will involve a single longer exposure. Examination of the specimens post-test, particularly at the crevice regions, will be the focus. Due to space constraints it is likely only one specimen will be employed per test. This will include optical microscopy, SEM, and cross-sectional SEM analysis. Experiments will collect the following data:

1. Hydrogen gas composition through air sampling and GC.

2. Weight change through weighing on 5 place balance before and after exposure.

3. Photographs of specimens after exposure.

4. SEM of specimen surface.

5. XRD of specimen surface.

6. Cross-sectional analysis through metallographic preparation and SEM when appropriate.

A matrix of conditions will be tested using conditions which are realistic for dry storage:

- Temperature range of 20 to $190^{\circ} \mathrm{C}$.

- Relative humidity range of 25 to $100 \%$.

- Contact with ceramic and stainless steel MCA washers. 


\subsubsection{Water Deliquescence}

In order to measure the small amount of water formed on aluminum, TGA will be used. The TGA has provisions to flow gas humidified by passing through a heated water bath. Experiments will be performed such that a switch from dry gas to humidified gas at the specified temperature as shown in Figure 5. The change in specimen weight due to water adsorption will be quantified from the TGA curve vs. time. Small specimens will be cut in order to fit into the TGA basket. After cutting the specimens will be pre-filmed with oxide as performed for Phase 1 specimens described earlier.

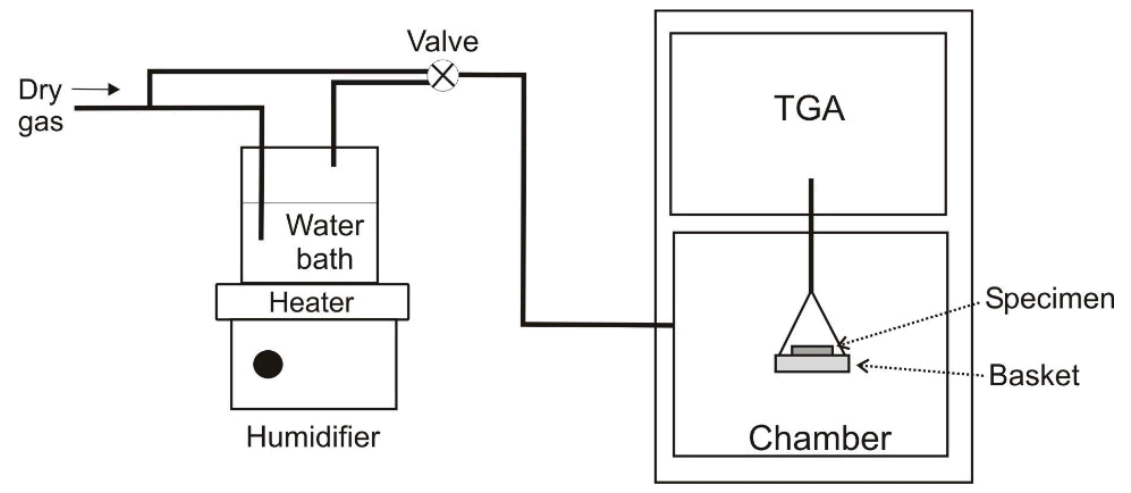

Figure 5. Experimental diagram of water deliquescence experiments.

A matrix of conditions will be tested using conditions which are realistic for dry storage:

- Temperature range of 20 to $190^{\circ} \mathrm{C}$.

- Relative humidity range of 25 to $100 \%$.

\subsubsection{Thermodynamic Modeling}

The following computational packages will be used for this work: ThermoCalc v.2018a (thermodynamic and phase equilibria, their self-consistent evaluation); OLI Stream Analyzer (aqueous systems in contact with wrought aluminum alloys AA6061T6 and AA6061O; AA5053; and AA1100) and casting aluminum alloy A356; OLI Corrosion Analyzer (analysis of fuel clad degradation mechanisms); and DFT package VASP v.5.4 ("Vienna Ab Initio Simulations Package).

\subsection{Procedures}

Performing experiments requires careful entry of all relevant information into the lab notebook. This includes recording experimental steps, specimen identification, calibration information, experimental time and date. If a specific set of tasks are to be performed in repetition, a copy can be pasted in the notebook and referred to. The important information from each experiment and or specimen needs to be clearly written in order for an independent person to understand what was done.

Specimens will have unique identifier (or ID\#), either from the specimen provider or applied by user before starting the experiment. This will allow each specimen to be tracked, particularly when a parallel operation such as specimen pre-treatment is performed. These marks will be recorded in notebook for each procedure followed. Ensure all specimens have an ID\# and record in the notebook clearly.

To determine the time exposed during testing, the user will record the start time and date once the experimented reaches set temperature and the stop time when the power to heaters are shut off. During sampling, user will record when a sample is drawn from the vessel. The user should utilize a clock from a smart phone that is connected to a wireless provider. 


\section{REQUIREMENTS}

\subsection{General}

All experimental activities outside of maintenance will be logged in a registered INL lab notebook. Record all pertinent information such as calibrations numbers and due dates and specimen identification numbers. After testing is complete, store specimens individually in containers such that their integrity is preserved. Label such that the experimental conditions are present on the container.

\subsection{Measurement}

In several of the experimental processes, calibrated instruments will be used. The person performing the experiment should record calibration specific information including calibration numbers and calibration due date.

\subsubsection{Use of Balances for Recording Mass}

All balances used will be within the calibration date (label on balance). Record calibration due date in notebook.

\subsubsection{Torque Wrench Use}

Torque wrenches are used to apply a specific force to MCA fixtures. The values provided in the procedure. Record set value and calibration data in notebook.

\subsubsection{Pipette Water Delivery User Standardization}

Pipettes are used to deliver a specified water dose to the chamber at the start of a test. In order to standardize that volume, the pipette must first be standardized. This is achieved measuring the desired volume into a vessel placed on a calibrated balance. Record three consecutive additions and average to determine weight. Without changing the pipette setting, repeat the actual volume to be added to the test vessel. Record the average weight during standardization as the amount of water added.

\section{ENVIRONMENT, SAFETY, AND HEALTH}

The test plan will per performed at REC facilities: INL Research Center (IRC) and the Energy Innovation Laboratory (EIL). The activities will be performed under two Laboratory Instructions (LI). Specimen pre-filming will be performed under LI-589 "Corrosion and Electrochemical Science". Corrosion testing will be performed under LI-610 "Oven and Furnace Operation". All requirements are contained within the appropriate LI.

\section{QUALITY ASSURANCE AND DATA/RECORD MANAGEMENT}

Quality assurance activities associated with Task 1 comply with all applicable requirements set forth in the INL Quality Assurance Program based on ASME NQA-1 2000. 


\section{SCHEDULE}

Table 2 provides the schedule for subtasks by quarter. The areas highlighted in blue indicate where that part of the project has scheduled activities. Descriptions of the subtasks are provided in Section 1.2. Table 2. Schedule of activities by quarter.

\begin{tabular}{|c|c|c|c|c|c|c|c|c|}
\hline $\begin{array}{c}\text { Sub task } \\
\quad \#\end{array}$ & Subtask & $\begin{array}{l}\text { FY18 } \\
\text { Q2 }\end{array}$ & $\begin{array}{c}\text { FY18 } \\
\text { Q3 }\end{array}$ & $\begin{array}{c}\text { FY18 } \\
\text { Q4 }\end{array}$ & $\begin{array}{c}\text { FY19 } \\
\text { Q1 }\end{array}$ & $\begin{array}{l}\text { FY19 } \\
\text { Q2 }\end{array}$ & $\begin{array}{c}\text { FY19 } \\
\text { Q3 }\end{array}$ & $\begin{array}{c}\text { FY19 } \\
\text { Q4 }\end{array}$ \\
\hline \multicolumn{9}{|c|}{ Task 1: Oxide film reactions and gas generation } \\
\hline $1.1 \mathrm{~A}$ & $\begin{array}{l}\text { Thermodynamic and kinetic } \\
\text { modeling }\end{array}$ & & & & & & & \\
\hline $1.1 \mathrm{~B}$ & $\begin{array}{l}\text { Experimental determination } \\
\text { of water reactions }\end{array}$ & & & & & & & \\
\hline $1.1 \mathrm{C}$ & $\begin{array}{l}\text { Interface }-\mathrm{H}_{2} \text { generation } \\
\text { rates as function of temp }\end{array}$ & & & & & & & \\
\hline \multicolumn{9}{|c|}{ Task 2: Accelerated corrosion mechanisms } \\
\hline $1.2 \mathrm{~A}$ & Localized corrosion & & & & & & & \\
\hline $1.2 \mathrm{~B}$ & $\begin{array}{l}\text { Capillary condensation and } \\
\text { deliquescence }\end{array}$ & & & & & & & \\
\hline
\end{tabular}

\section{REFERENCES}

1. M.D. Argyle, Aluminum Clad Spent Nuclear Fuel: Technical Considerations and Challenges for Extended (>50 Years) Dry Storage, DOE/ID RPT 1575, 2017.

2. M.J. Connolly, Aluminum Clad Spent Nuclear Fuel Long Term Dry Storage Technical Issues Action Plan - Technical and Engineering Activities, INL/EXT-17-43908, 2017.

3. A.K. Wertsching, Material Interactions on Canister Integrity during Storage and Transport, REP-104, 2007.

4. A. Christensen, The Irradiated Fuel Storage Facility Maximum Heat Load and Resulting Maximum Temperatures when the Ventilation System is not Operating, EDF-2760, 2003.

5. Corrosion Analysis for Non-Dried ATR Aluminum Plate Fuels Placed in CS Canisters, EDF-7936, 2006. 